\title{
Combining Constrained Heptapeptide Cassettes With Computational Design to Create Coiled-coil Targeting Helical Peptides
}

\author{
Alexander Lathbridge ${ }^{1}$ and Jody M. Mason ${ }^{1,2}$ \\ ${ }^{1}$ Dept of Biology and Biochemistry, University of Bath, Claverton Down, Bath BA2 7AY \\ ${ }^{2}$ To whom correspondence should be addressed: j.mason@bath.ac.uk \\ Running title: Heptapeptide cassettes \\ *Corresponding author: Jody M. Mason (E: j.mason@bath.ac.uk; T: +441225386867) \\ Keywords: Coiled coil; Peptide antagonist, peptide cassettes, constrained peptides; heptads; Activator \\ Protein-1; transcription factor.
}

\section{Supporting Information}

Electrospray Mass Spectroscopy Data of Linear and Lactamised Peptides - All 32 peptides provided an excellent agreement between the expected and observed mass in both linear and lactamised versions of peptide (Figure S1, peptides 1-4; Figure S2, Peptides 5-8; Figure S3, peptides 9-12; Figure S4, peptides 13-16).

Peptide Sequences - All synthesised and characterised peptides were amidated and acetylated.

CJUn: $\quad \underline{A S R I A R L E E K V K T L K A Q N Y E L A S T A N M L R E Q V A Q L K G A P ~}$

1-3-16-7 : YEIKALEDELKALEDKNKALKDEIKALKD

6-2-13-5: YKVKALEDKIKALEDENKALEDEVKALED

Sequence Specificity - All cassettes exhibited an increase in helicity when lactamised. However, the extent of helical gain varied, with the ability of certain residues to tolerate lactamisation over others being less clear (Fig S5-S6). As shown in Figure 3b, a wide range of $\mathrm{fH}$ increase due to lactamisation was observed. Since the possible amino acids combinations at $\boldsymbol{a} / \boldsymbol{e} / \boldsymbol{g}$ positions were limited, only partial interpretations can be drawn from the electrostatic and core configurations in optimising cassette stability. This does however present an opportunity to optimise the computational techniques employed. As previously shown, ${ }^{1}$ bCIPA is capable of being trained on a specific subset of coiled coil forming sequences. With further experimental exploration of the cassette library, it may be possible to extract the predictors and develop a more specific prediction algorithm for this use. 
Conjugated Peptide Lactamisation - As shown in Figures S7 and S8, both of the peptides exhibited a decrease in mass of $36 \mathrm{Da}$, indicating that both lactam bridges successfully formed between Asp and Lys, resulting in the loss of two water molecules.

Although peptides truncated less than 29 residues have been explored previously ${ }^{2-7}$ with a focus on maintaining stability, it was decided to conjugate four cassettes to maximise the potential interpretation and to maintain a quantifiable stability with the target.

Table S1. Electrospray Mass Spectroscopy Data of Linear and Lactamised Peptides

\begin{tabular}{|l|l|l|l|l|l|l|}
\hline Peptide & Sequence & $\begin{array}{l}\text { Expected } \\
\text { Linear Mass }\end{array}$ & $\begin{array}{c}\text { Observed } \\
\text { Linear Mass }\end{array}$ & $\begin{array}{c}\text { Expected } \\
\text { Cyclic Mass }\end{array}$ & $\begin{array}{c}\text { Observed } \\
\text { Cyclic Mass }\end{array}$ & $\begin{array}{c}\text { Mass Change } \\
\text { Linear - Cyclic }\end{array}$ \\
\hline $\mathbf{1}$ & YEIKALED & 1021.50 & $\mathbf{1 0 2 1 . 5 3}$ & 1003.50 & $\mathbf{1 0 0 3 . 5 2}$ & 18.01 \\
\hline $\mathbf{2}$ & YKIKALED & 1020.55 & $\mathbf{1 0 2 0 . 5 8}$ & 1002.55 & $\mathbf{1 0 0 2 . 5 7}$ & 18.01 \\
\hline $\mathbf{3}$ & YELKALED & 1021.50 & $\mathbf{1 0 2 1 . 5 3}$ & 1003.50 & $\mathbf{1 0 0 3 . 5 3}$ & 18.00 \\
\hline $\mathbf{4}$ & YKLKALED & 1021.50 & $\mathbf{1 0 2 0 . 5 8}$ & 1003.50 & $\mathbf{1 0 0 2 . 5 7}$ & 18.01 \\
\hline $\mathbf{5}$ & YEVKALED & 1007.48 & $\mathbf{1 0 0 7 . 5 1}$ & 989.48 & $\mathbf{9 8 9 . 5 1}$ & 18.00 \\
\hline $\mathbf{6}$ & YKVKALED & 1006.53 & $\mathbf{1 0 0 6 . 5 6}$ & 988.53 & $\mathbf{9 8 8 . 5 6}$ & 18.00 \\
\hline $\mathbf{7}$ & YEIKALKD & 1020.55 & $\mathbf{1 0 2 0 . 5 7}$ & 1002.55 & $\mathbf{1 0 0 2 . 5 7}$ & 18.00 \\
\hline $\mathbf{8}$ & YKIKALKD & 1019.60 & $\mathbf{1 0 1 9 . 6 2}$ & 1001.60 & $\mathbf{1 0 0 1 . 6 2}$ & 18.00 \\
\hline $\mathbf{9}$ & YELKALKD & 1020.55 & $\mathbf{1 0 2 0 . 5 8}$ & 1002.55 & $\mathbf{1 0 0 2 . 5 7}$ & 18.01 \\
\hline $\mathbf{1 0}$ & YKLKALKD & 1019.60 & $\mathbf{1 0 1 9 . 6 2}$ & 1001.60 & $\mathbf{1 0 0 1 . 6 2}$ & 18.01 \\
\hline $\mathbf{1 1}$ & YEVKALKD & 1006.53 & $\mathbf{1 0 0 6 . 5 7}$ & 988.53 & $\mathbf{9 8 8 . 5 5}$ & 18.01 \\
\hline $\mathbf{1 2}$ & YKVKALKD & 1005.59 & $\mathbf{1 0 0 5 . 6 1}$ & 987.59 & $\mathbf{9 8 7 . 6 1}$ & 18.01 \\
\hline $\mathbf{1 3}$ & YENKALED & 1022.46 & $\mathbf{1 0 2 2 . 4 8}$ & 1004.46 & $\mathbf{1 0 0 4 . 4 8}$ & 18.00 \\
\hline $\mathbf{1 4}$ & YKNKALED & 1021.51 & $\mathbf{1 0 2 1 . 5 3}$ & 1003.51 & $\mathbf{1 0 0 3 . 5 2}$ & 18.01 \\
\hline $\mathbf{1 5}$ & YENKALKD & 1021.51 & $\mathbf{1 0 2 1 . 5 3}$ & 1003.51 & $\mathbf{1 0 0 3 . 5 3}$ & 18.01 \\
\hline $\mathbf{1 6}$ & YKNKALKD & 1020.56 & $\mathbf{1 0 2 0 . 5 9}$ & 1002.56 & $\mathbf{1 0 0 2 . 5 8}$ & 18.01 \\
\hline
\end{tabular}

Mass spectrometry data for cassettes 1-16. For each peptide the predicted mass, observed mass for both linear and cyclic forms of each cassette are shown. As expected, the difference between the linear and lactamised form of the cassette accounts for the loss of one water molecule in every case. 
Table S2. Helical and Thermal Stability of Linear and Lactamised Peptides

\begin{tabular}{|c|c|c|c|}
\hline Peptide & $\mathbf{f H}(\%)$ & $\mathbf{2 2 2} \mathbf{~ n m} / \mathbf{2 0 8} \mathbf{~ n m}$ & $\mathbf{T}_{\mathbf{m}}\left({ }^{\circ} \mathbf{C}\right)$ \\
\hline cJun & 29.1 & 0.73 & 25.7 \\
\hline 1-3-16-7 Linear & 65.3 & 0.89 & 29.13 \\
\hline 1-3-16-7 Lactamised & 71.4 & 1.01 & N/A \\
\hline 6-2-13-5 Linear & 18.2 & 0.44 & N/A \\
\hline 6-2-13-5 Lactamised & 20.4 & 0.69 & 34 \\
\hline 1-3-16-7 Linear : cJun & 55.2 & 0.87 & 57.2 \\
\hline 1-3-16-7 Lactamised : cJun & 52.0 & 0.90 & 18.9 \\
\hline 6-2-13-5 Linear : cJun & 24.9 & 0.60 & 29.2 \\
\hline
\end{tabular}

A comparison of the full length peptide complexes - with their fractional helicty, $222 \mathrm{~nm} / 208 \mathrm{~nm}$ ratio, and transition midpoint $\left(T_{m}\right)$ values.

\section{Computational Processing}

All software was run on Python on a 64-bit x64-based processor Windows machine with 12 GB of RAM as described previously ${ }^{1}$.

Figure S1. Electrospray Mass Spectrometry data from the purified cassettes 1-4 demonstrating a loss of $18 \mathrm{Da}$ between the linear and successfully lactamised forms of cassette 1 (A/B), cassette 2 (C/D), cassette $3(\mathrm{E} / \mathrm{F})$, and cassette $4(\mathrm{G} / \mathrm{H})$.

Figure S2. Electrospray Mass Spectrometry data from the purified cassettes 5-8 demonstrating a loss of $18 \mathrm{Da}$ between the linear and successfully lactamised forms of cassette 5 (A/B), cassette 6 (C/D), cassette $7(E / F)$, and cassette $8(G / H)$.

Figure S3. Electrospray Mass Spectrometry data from the purified cassettes 9-12 demonstrating a loss of $18 \mathrm{Da}$ between the linear and successfully lactamised forms of cassette 9 (A/B), cassette 10 $(C / D)$, cassette $11(E / F)$, and cassette $12(G / H)$.

Figure S4. Electrospray Mass Spectrometry data from the purified cassettes 13-16 demonstrating a loss of $18 \mathrm{Da}$ between the linear and successfully lactamised forms of cassette 13 (A/B), cassette 14 $(C / D)$, cassette $15(E / F)$, and cassette $16(G / H)$.

Figure S5. Thermal spectra for cassettes 1-16 in linear form. Spectra were initially measured at $20^{\circ} \mathrm{C}$ (black) and in $10^{\circ} \mathrm{C}$ increments to $90^{\circ} \mathrm{C}$ (red) and then post melt at $20^{\circ} \mathrm{C}$ (blue) at a total peptide concentration of $150 \mu \mathrm{M}$ and presented as mean residue ellipticity (MRE). All experiments were performed in $10 \mathrm{mM}$ potassium phosphate and $100 \mathrm{mM}$ potassium fluoride ( $\mathrm{pH}$ 7). For all cases, the 
linear forms were characterised as having a random coil profile at $20^{\circ} \mathrm{C}$, both prior to thermal denaturation and as post-melt samples, with disorder persisting at $90^{\circ} \mathrm{C}$.

Figure S6. Thermal spectra for cassettes 1-16 in lactamised form. Spectra were initially measured at $20^{\circ} \mathrm{C}$ (black) and in $10^{\circ} \mathrm{C}$ increments to $90^{\circ} \mathrm{C}$ (red) and then post melt at $20^{\circ} \mathrm{C}$ (blue) at a total peptide concentration of $150 \mu \mathrm{M}$ and presented as mean residue ellipticity (MRE). All experiments were performed in $10 \mathrm{mM}$ potassium phosphate and $100 \mathrm{mM}$ potassium fluoride ( $\mathrm{pH}$ 7). In all cases, lactamised cassettes presented as $\alpha$-helical at $20^{\circ} \mathrm{C}$ and returned to within $5 \%$ of the same helical signature as post-melt samples, with an average helicity of $48 \%$. Consistent with lactamisation as a potent helix-inducer, at $90^{\circ} \mathrm{C}$ helicity was retained with an average $\mathrm{fH}$ of $38 \%$.

Figure S7. Electrospray Mass Spectrometry data from the purified full-length 1-3-16-7 demonstrates the peptide to have the expected mass of $3415.91 \mathrm{Da}$ as a linear sequence $(A)$ and the expected mass of 3379.91 Da when lactamised (B). The loss of 36 Da demonstrates that there has been successful successful lactamisation at both termini consistent with the loss of two water molecules.

Figure S8. Electrospray Mass Spectrometry data from the purified full-length 6-2-13-5 demonstrates the peptide to have the expected mass of $3388.79 \mathrm{Da}$ as a linear sequence $(A)$ and the expected mass of 3352.79 Da when lactamised (B). The loss of 36 Da demonstrates that there has been successful lactamisation at both termini consistent with the loss of two water molecules.

\section{References}

(1) Lathbridge, A., and Mason, J. M. (2018) Computational Competitive and Negative Design to Derive a Specific cJun Antagonist. Biochemistry 57, 6108-6118.

(2) Rao, T., Ruiz-Gómez, G., Hill, T. A., Hoang, H. N., Fairlie, D. P., and Mason, J. M. (2013) Truncated and Helix-Constrained Peptides with High Affinity and Specificity for the cFos Coiled-Coil of AP-1. PLoS One 8, e59415.

(3) Baxter, D., Perry, S. R., Hill, T. A., Kok, W. M., Zaccai, N. R., Brady, R. L., Fairlie, D. P., and Mason, J. M. (2017) Downsizing Proto-oncogene cFos to Short Helix-Constrained Peptides That Bind Jun. ACS Chem. Biol. 12, 2051-2061.

(4) Hoang, H. N., Driver, R. W., Beyer, R. L., Hill, T. A., D. de Araujo, A., Plisson, F., Harrison, R. S., Goedecke, L., Shepherd, N. E., and Fairlie, D. P. (2016) Helix Nucleation by the Smallest Known $\alpha$-Helix in Water. Angew. Chemie - Int. Ed. 55, 8275-8279.

(5) De Araujo, A. D., Hoang, H. N., Kok, W. M., Diness, F., Gupta, P., Hill, T. A., Driver, R. W., Price, D. 
A., Liras, S., and Fairlie, D. P. (2014) Comparative $\alpha$-helicity of cyclic pentapeptides in water. Angew. Chemie - Int. Ed. 53, 6965-6969.

(6) Shepherd, N. E., Abbenante, G., and Fairlie, D. P. (2004) Consecutive cyclic pentapeptide modules form short alpha-helices that are very stable to water and denaturants. Angew. Chemie - Int. Ed. 43, 2687-2690.

(7) Mazzier, D., Peggion, C., Toniolo, C., and Moretto, A. (2014) Enhancement of the helical content and stability induced in a linear oligopeptide by an $\mathrm{i}, \mathrm{i}+4$ intramolecularly double stapled, overlapping, bicyclic [31, 22, 5]-(E)ene motif. Biopolym. - Pept. Sci. Sect. 102, 115-123. 


\section{Figure S1}

LINEAR
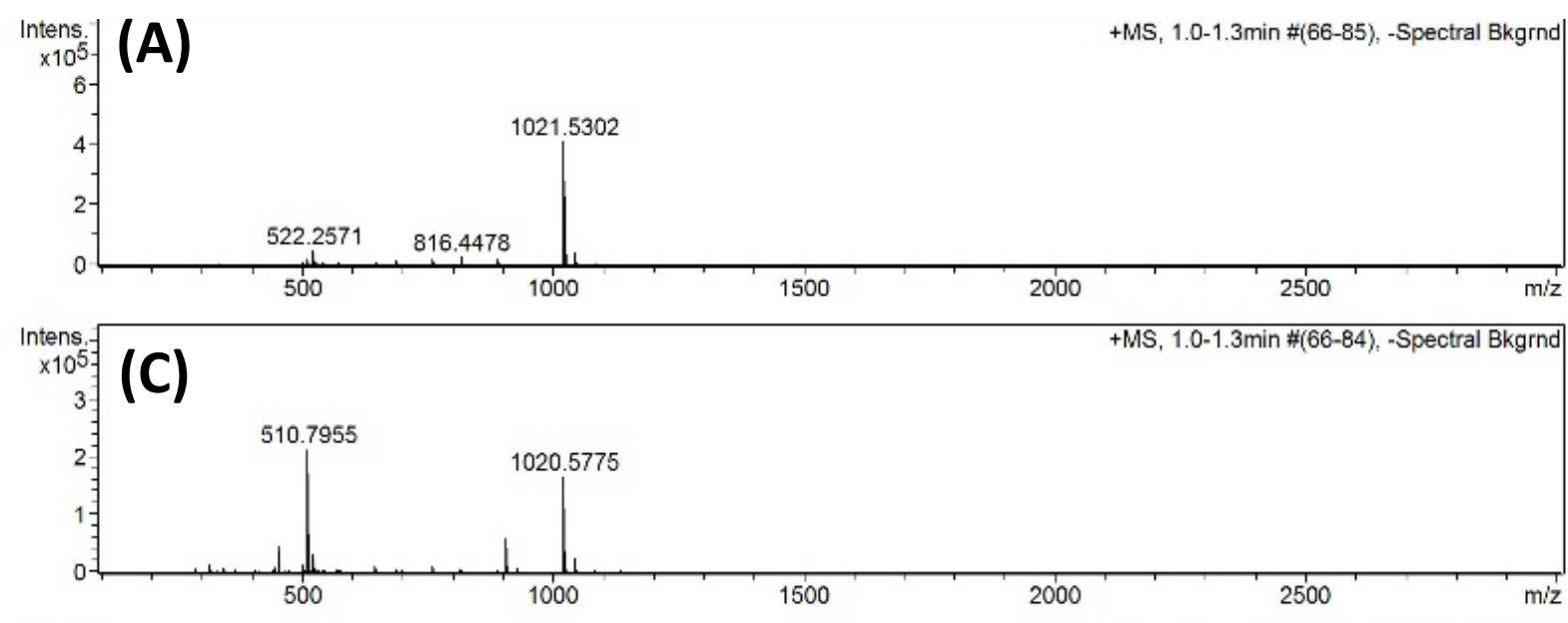

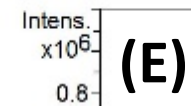
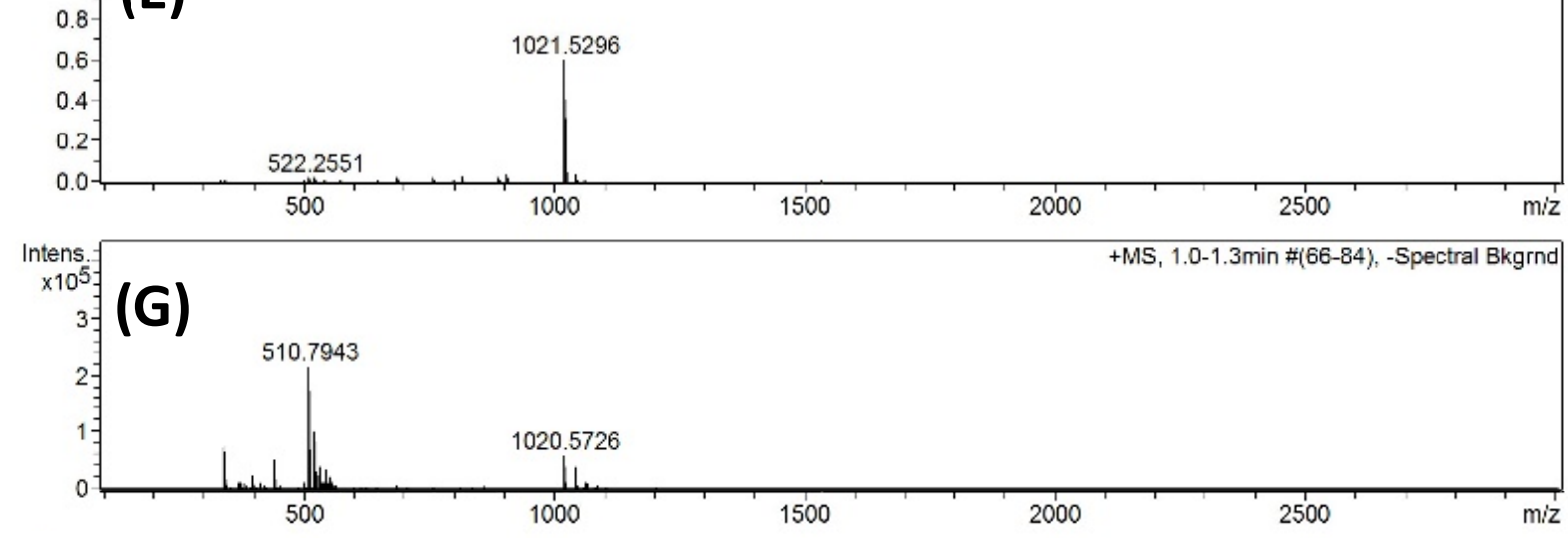

LACTAMISED

(B)

1

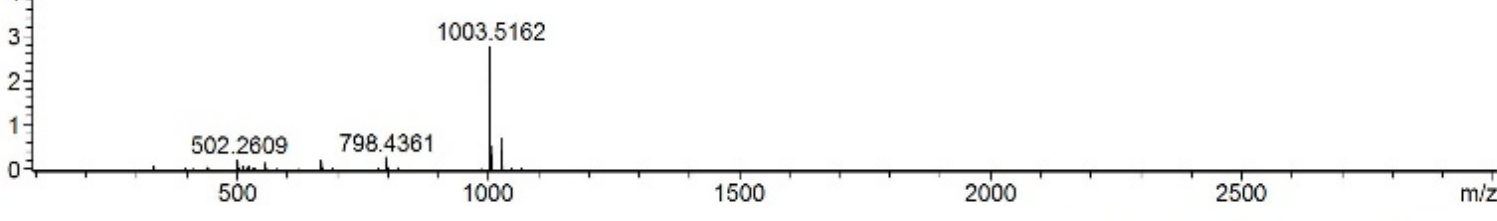

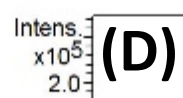

2

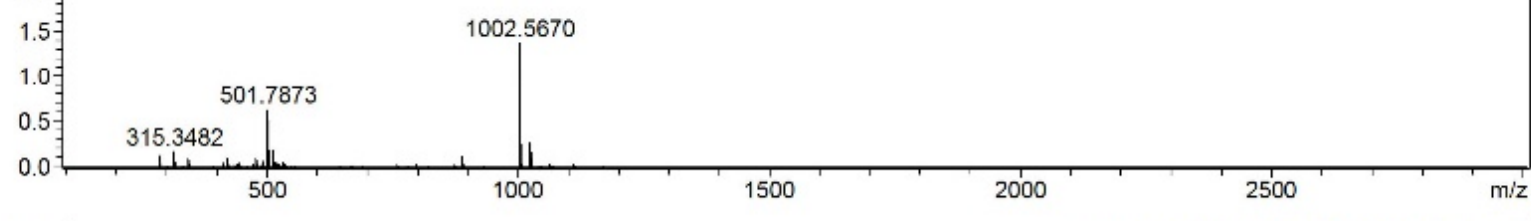

Intenn:

3
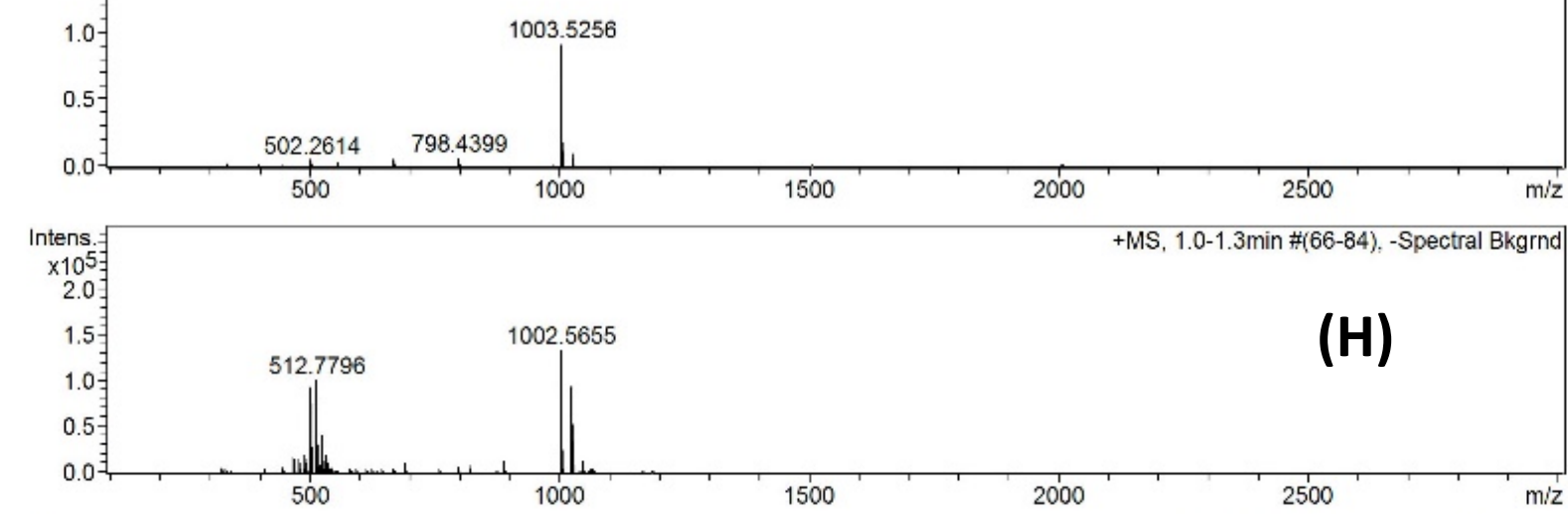


\section{Figure S2}

LINEAR
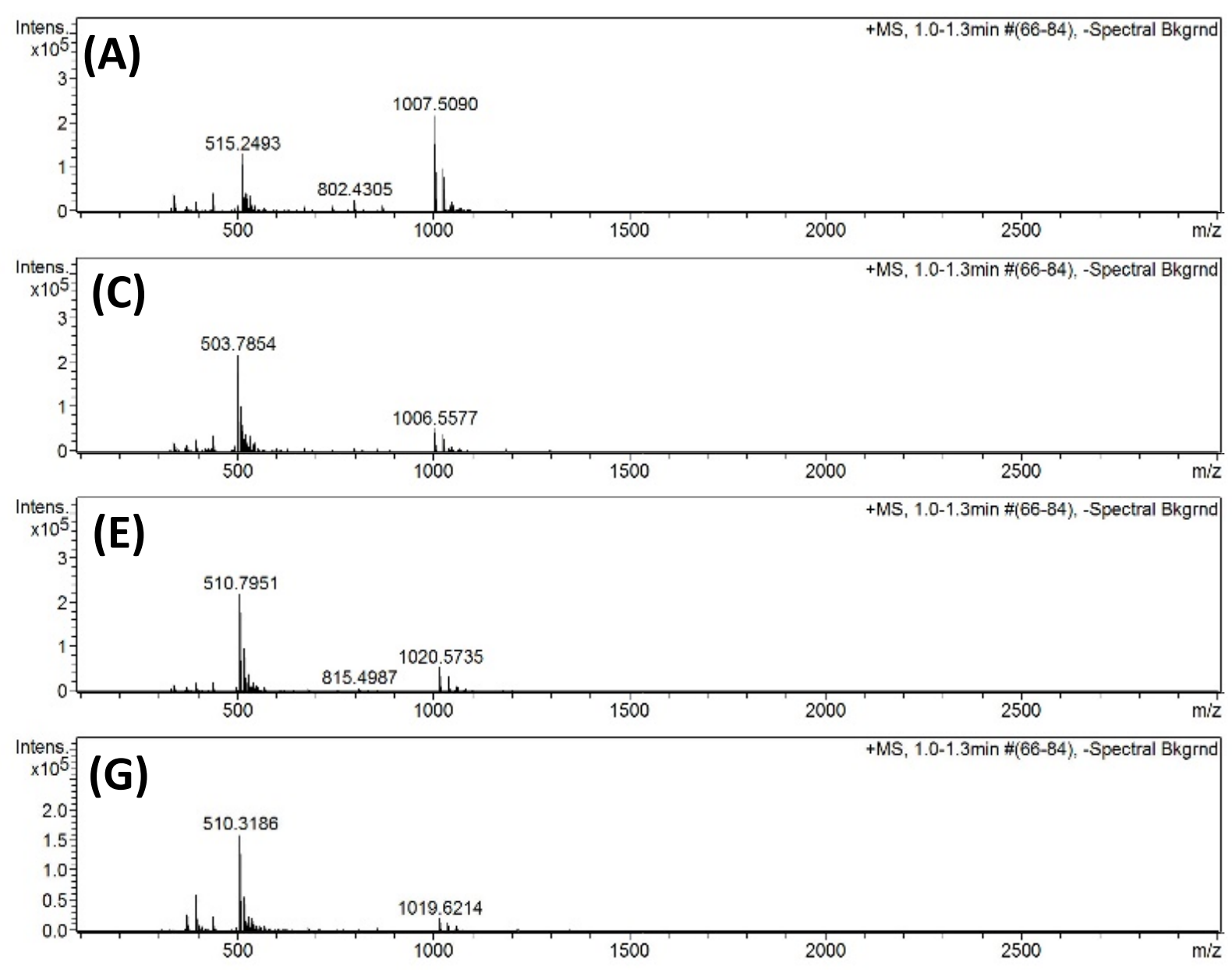

\section{LACTAMISED}

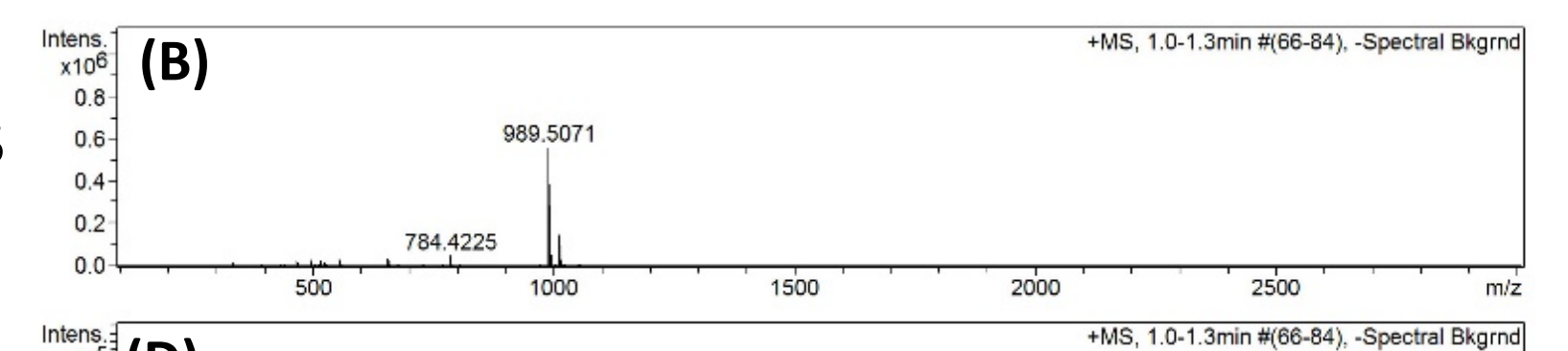

6
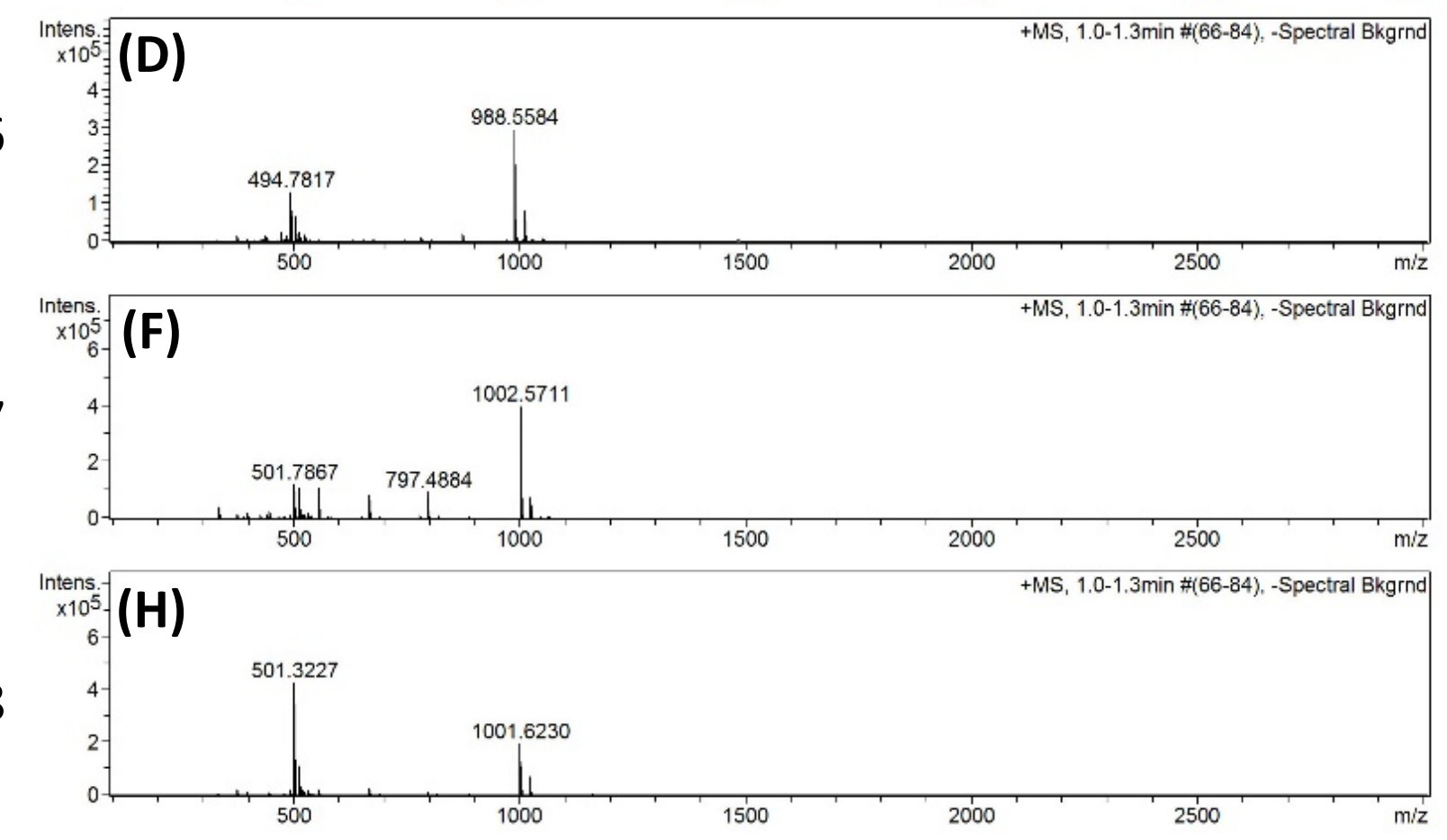


\section{Figure S3}

LINEAR
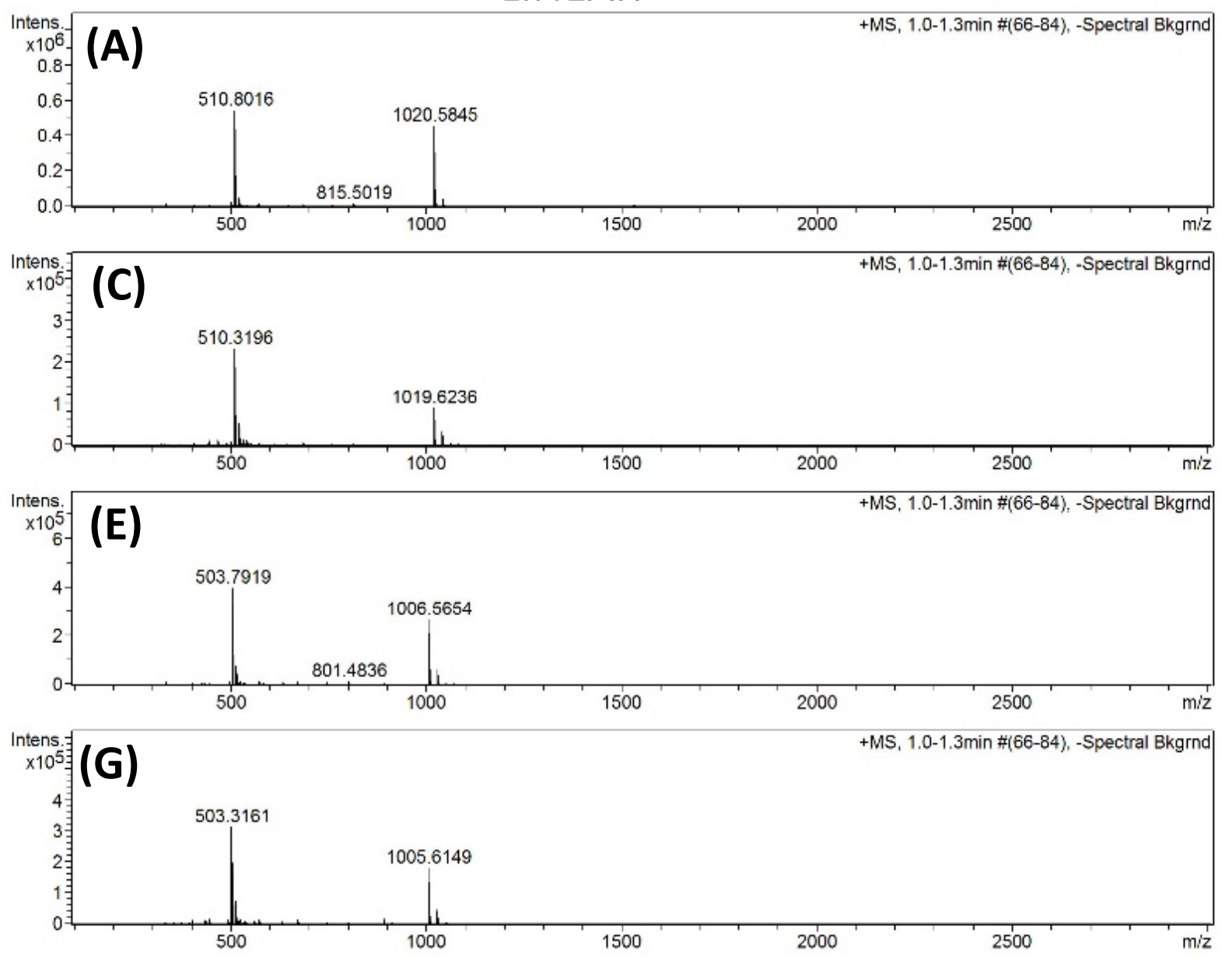

LACTAMISED
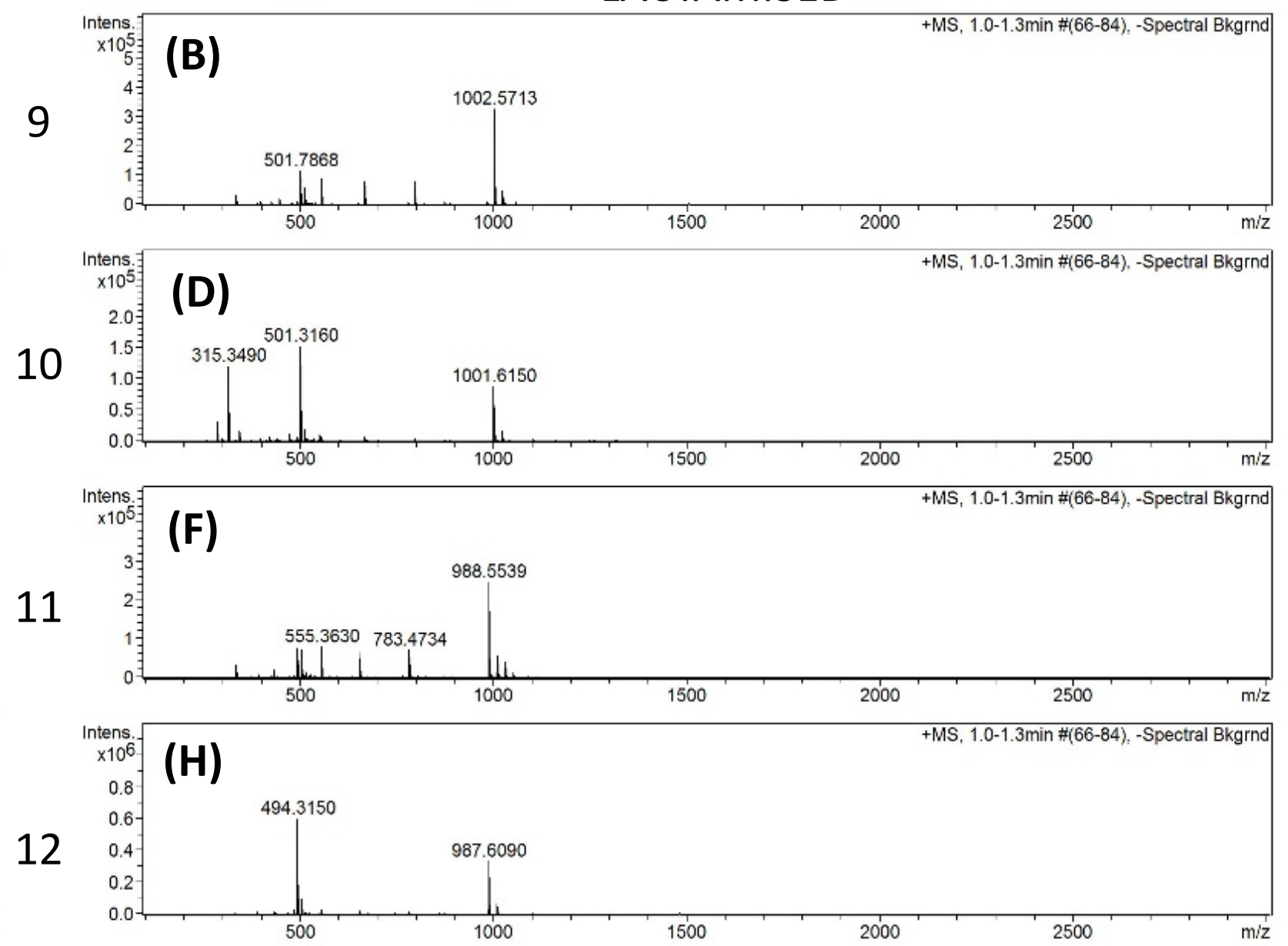


\section{Figure S4}

\section{LINEAR}
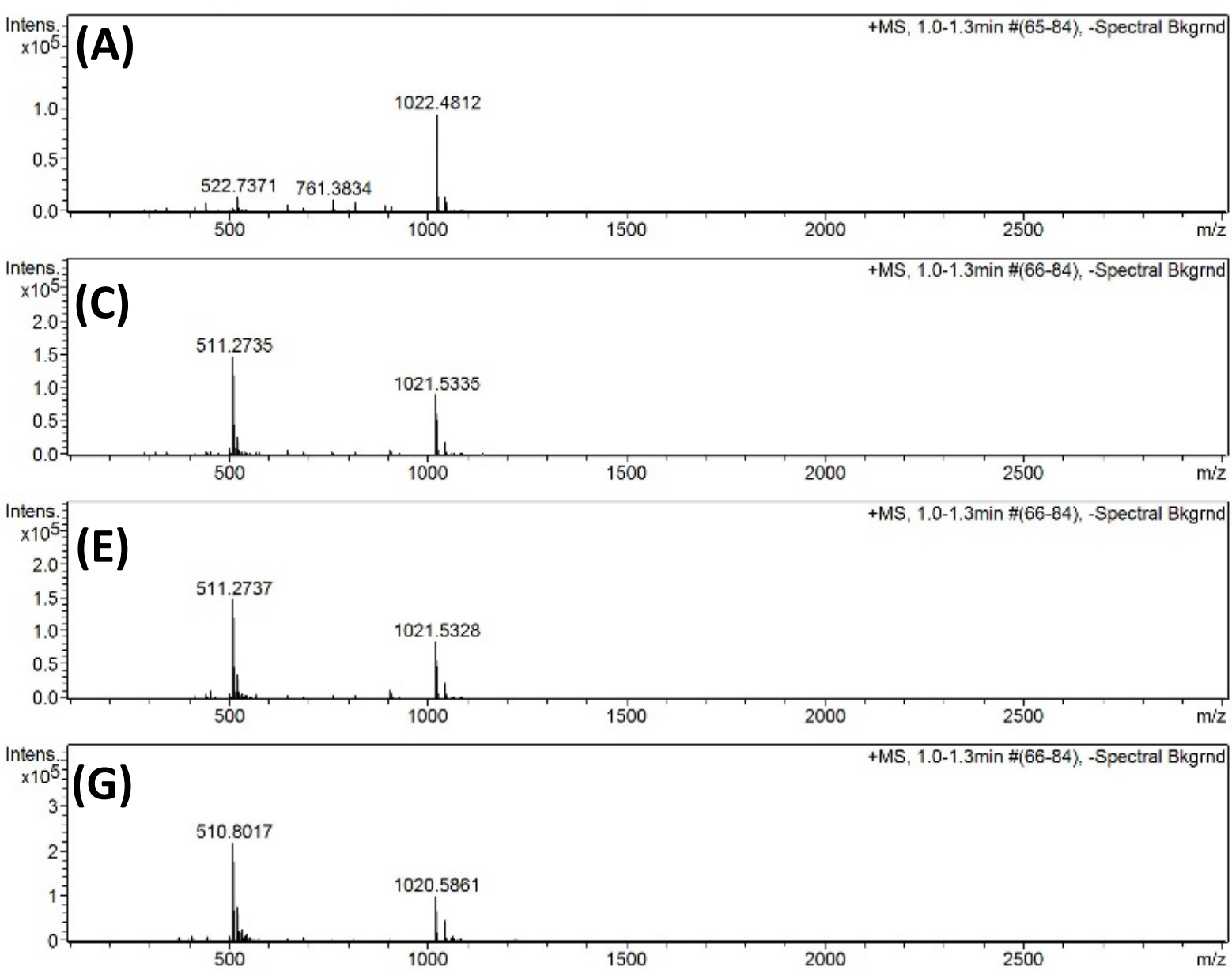

\section{LACTAMISED}
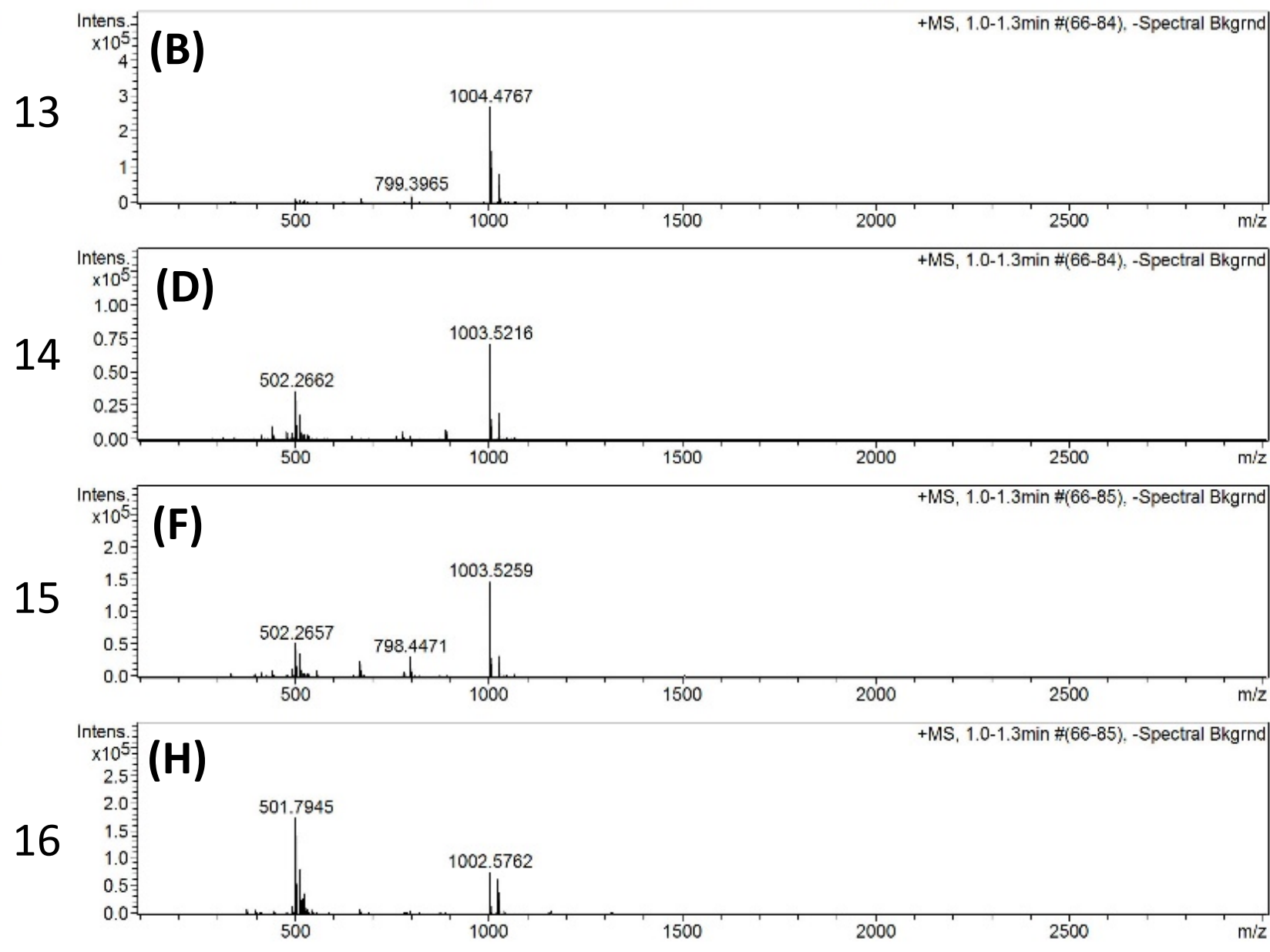
(1)

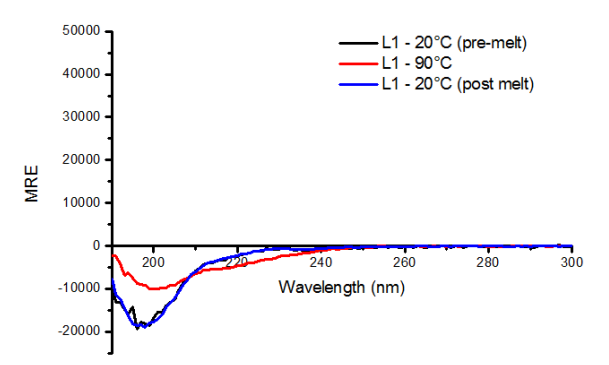

(5)

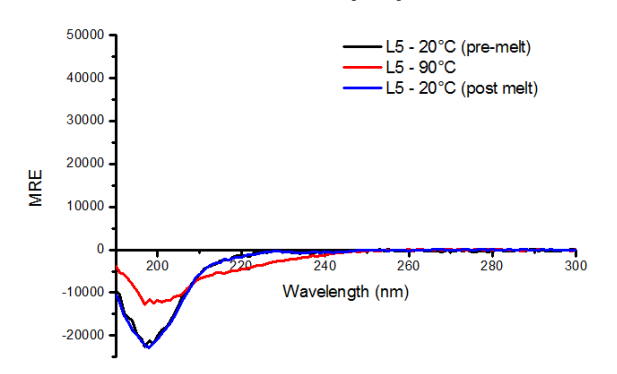

(9)

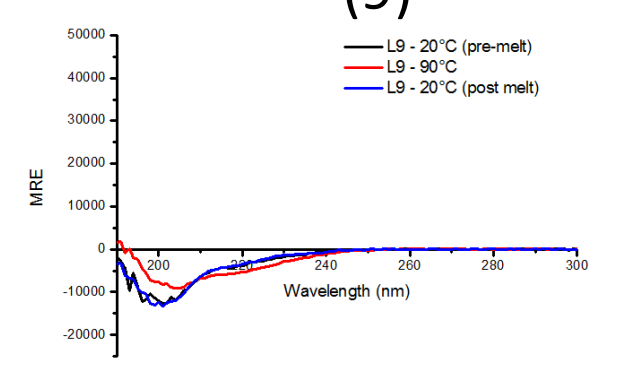

(13)

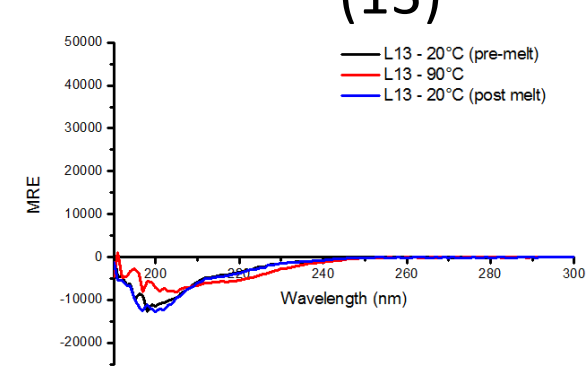

(2)

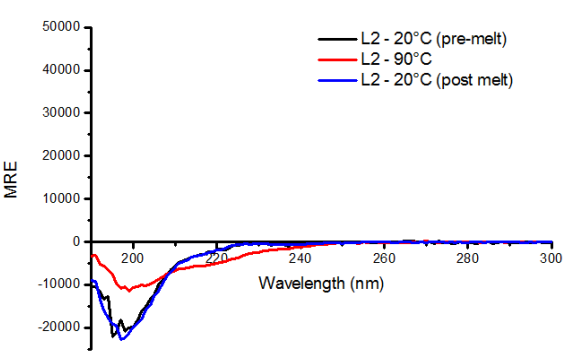

(6)

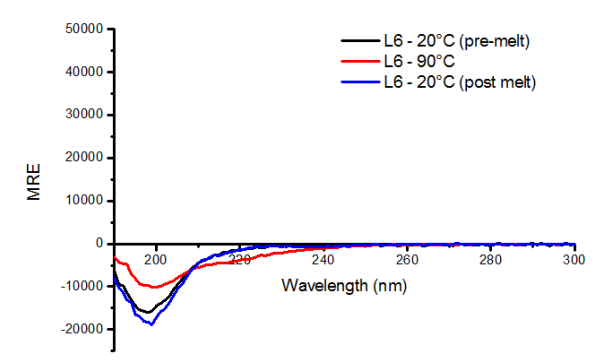

(10)

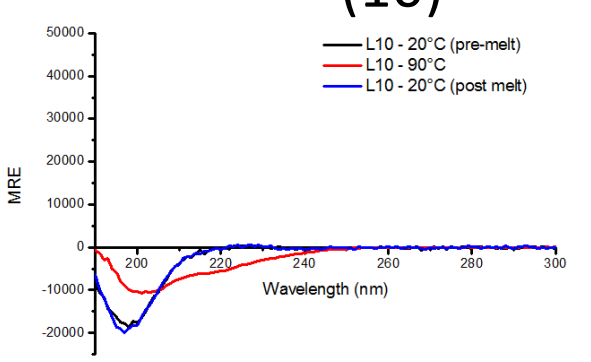

(14)

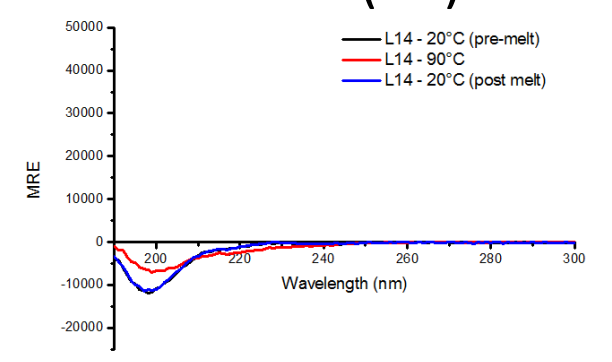

(3)

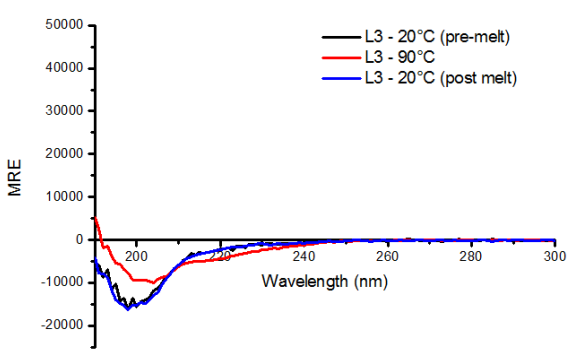

(7)

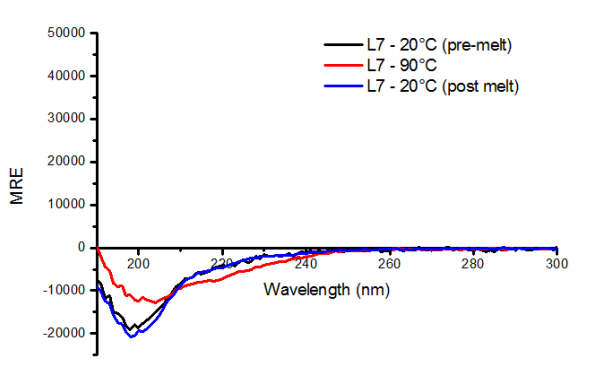

(11)

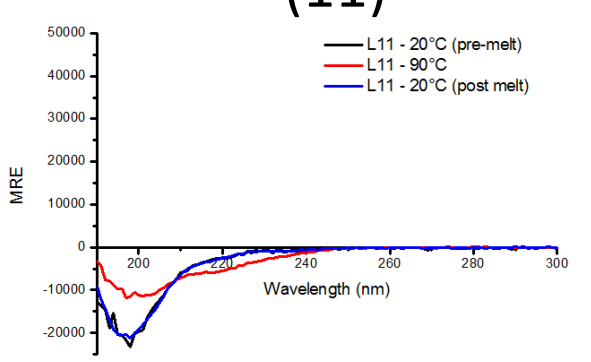

(15)

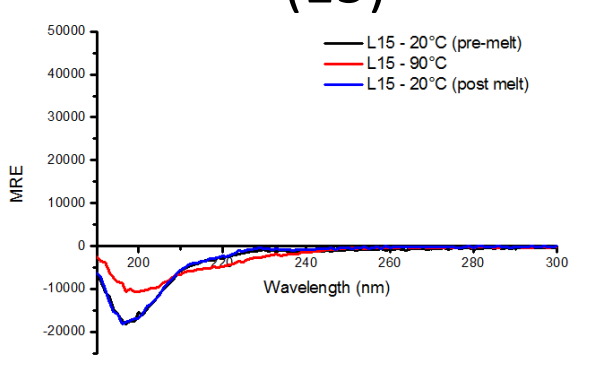

(4)

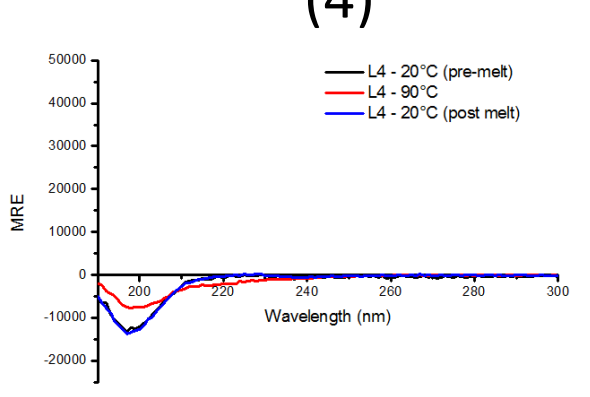

(8)

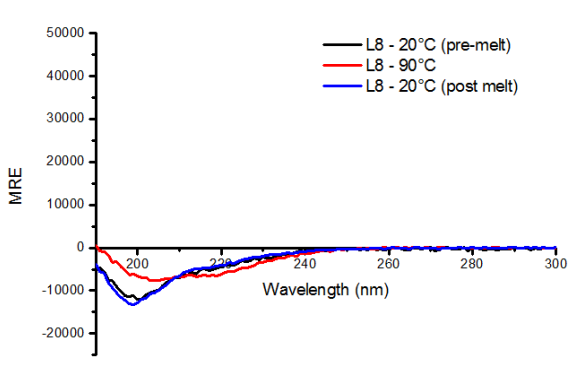

(12)

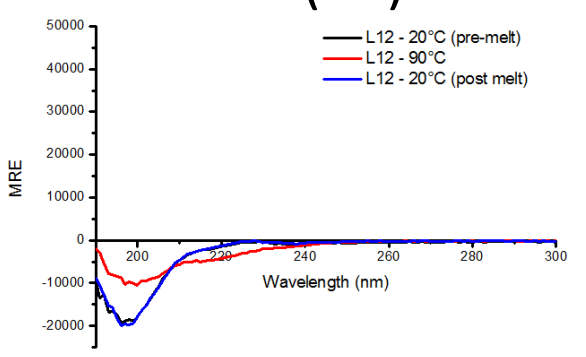

(16)

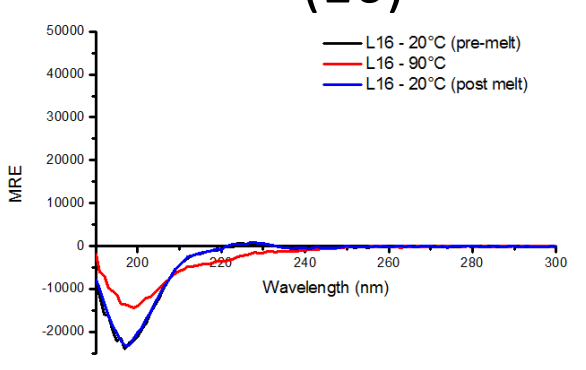


(1)

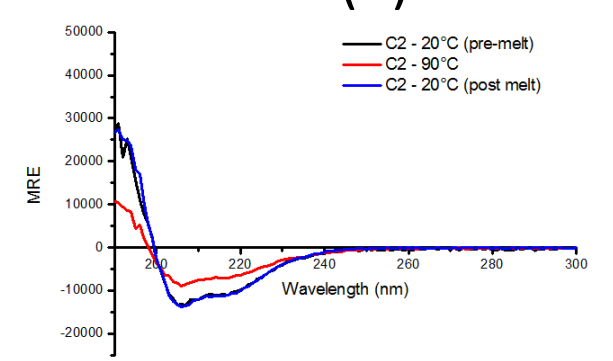

(5)

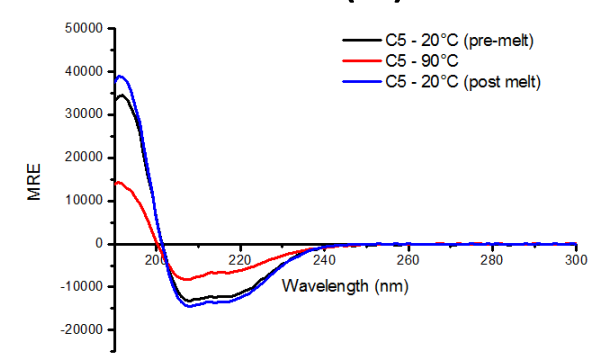

(9)

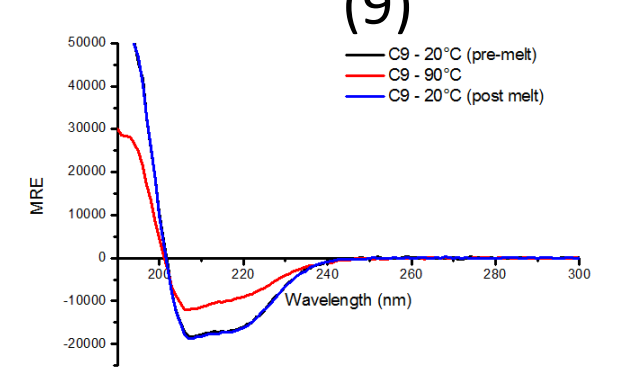

(13)

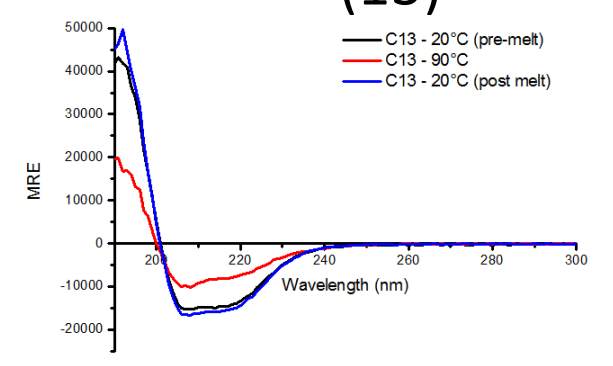

(2)

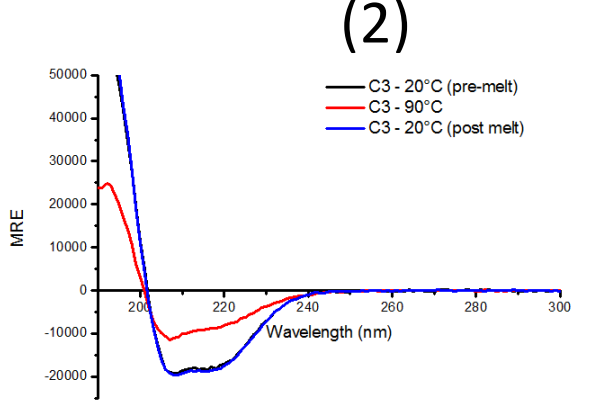

(6)

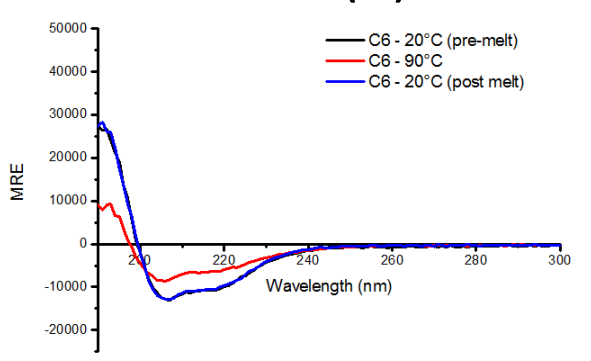

(10)

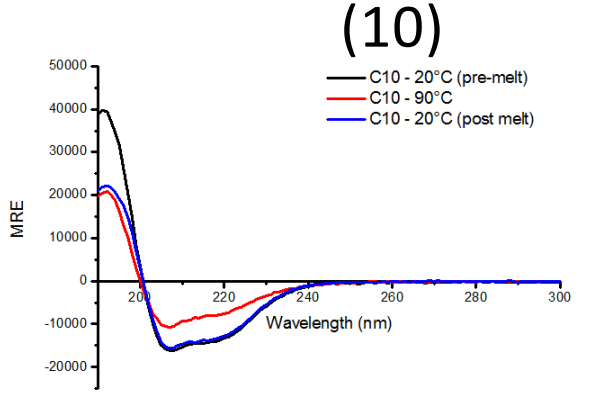

(14)

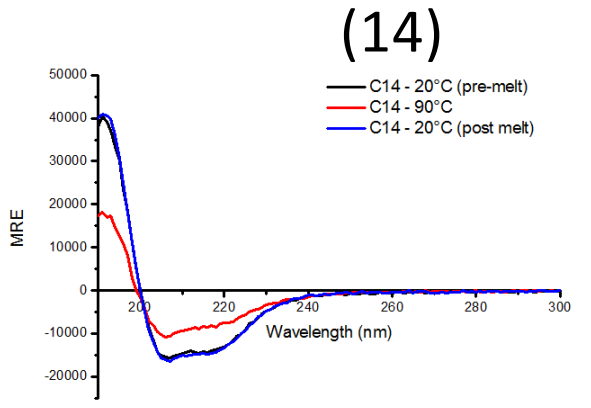

(3)

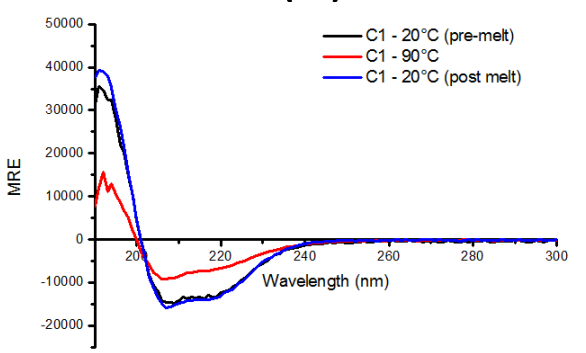

(7)

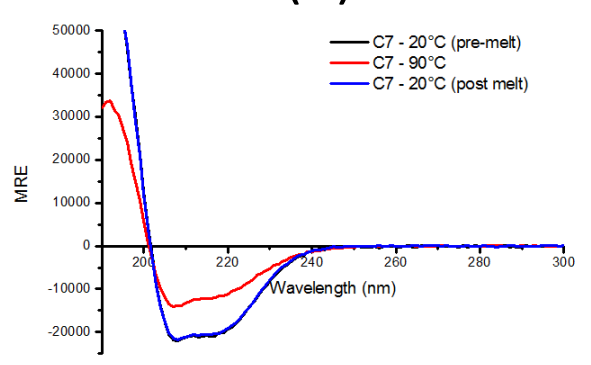

(11)

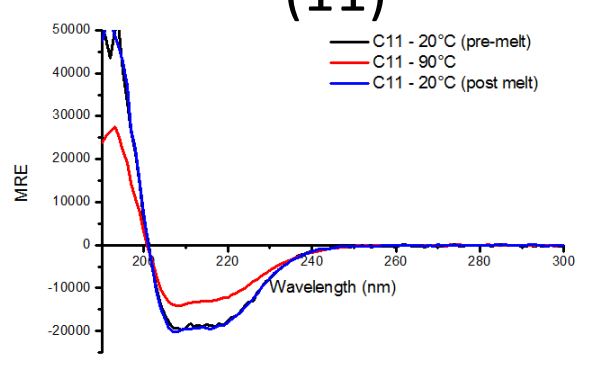

(15)

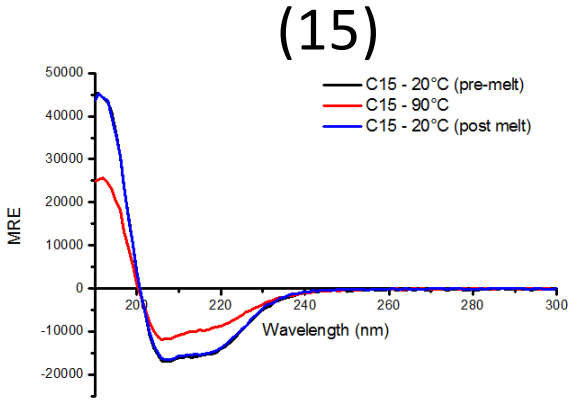

(4)

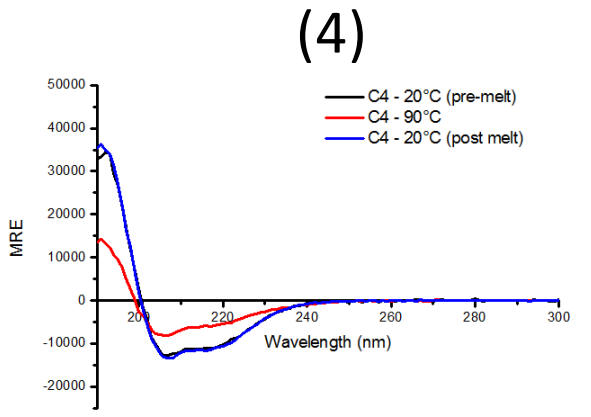

(8)

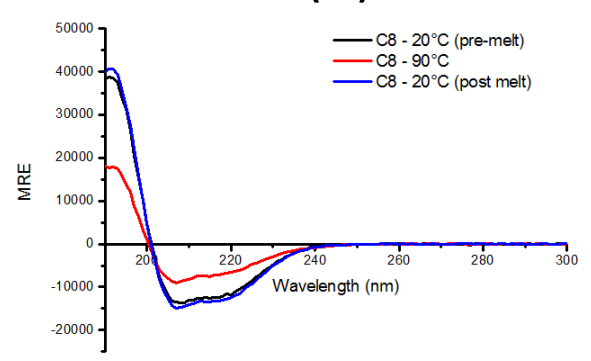

(12)

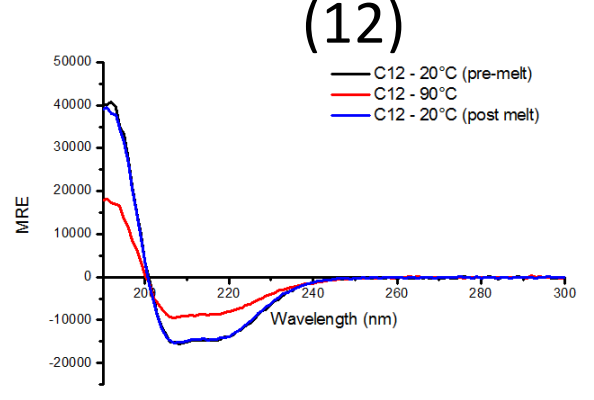

(16)

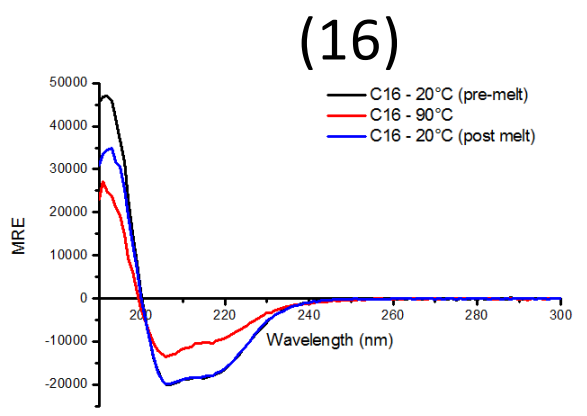




\section{Figure S7}
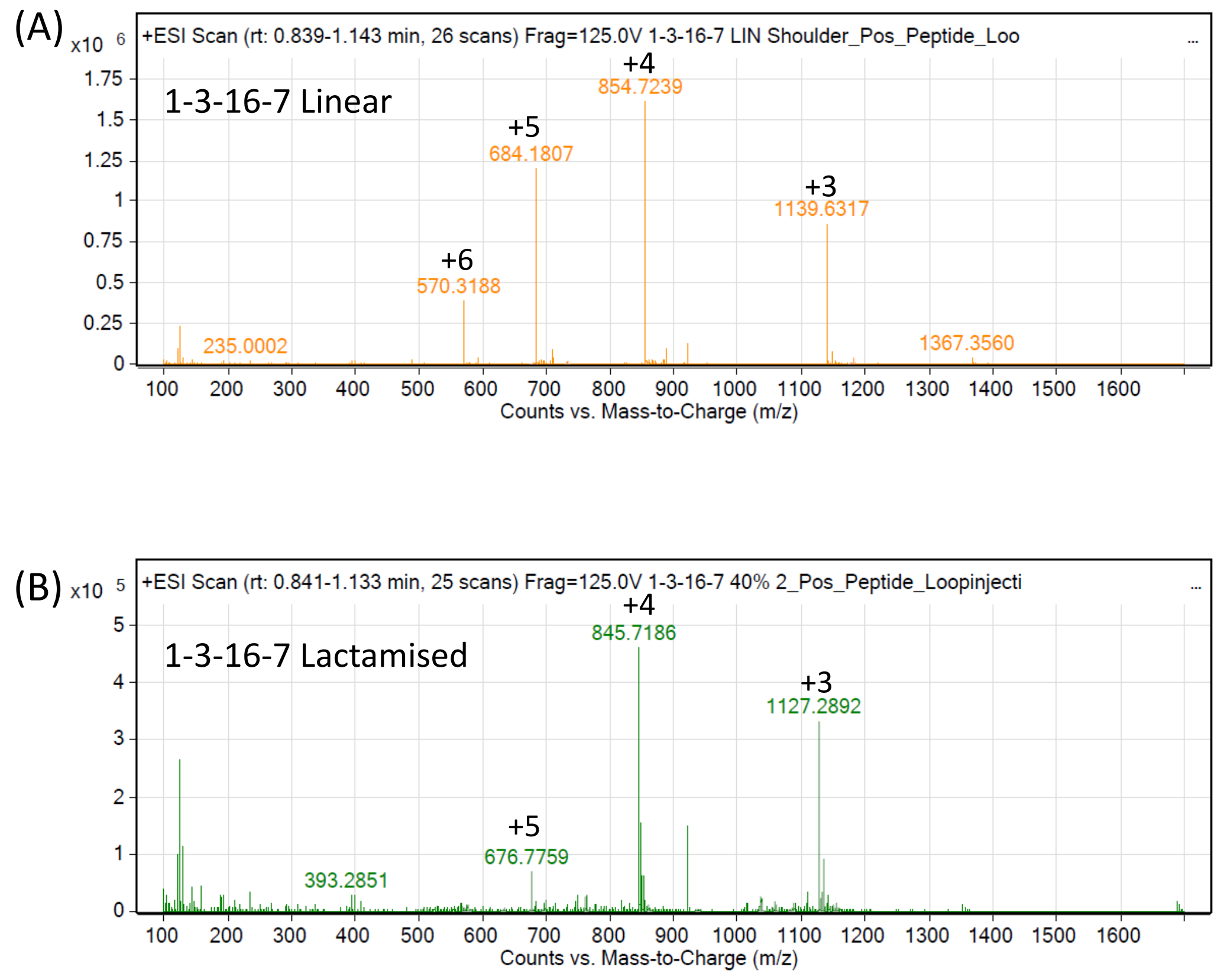


\section{Figure S8}

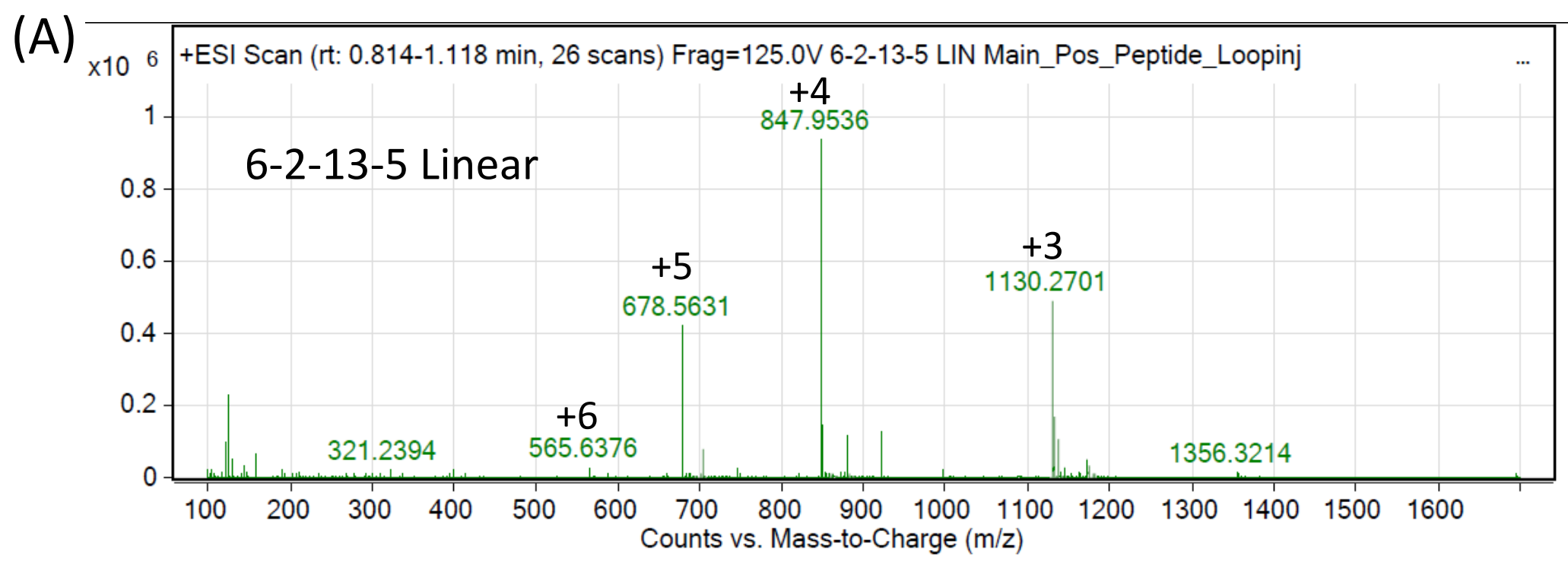

(B)

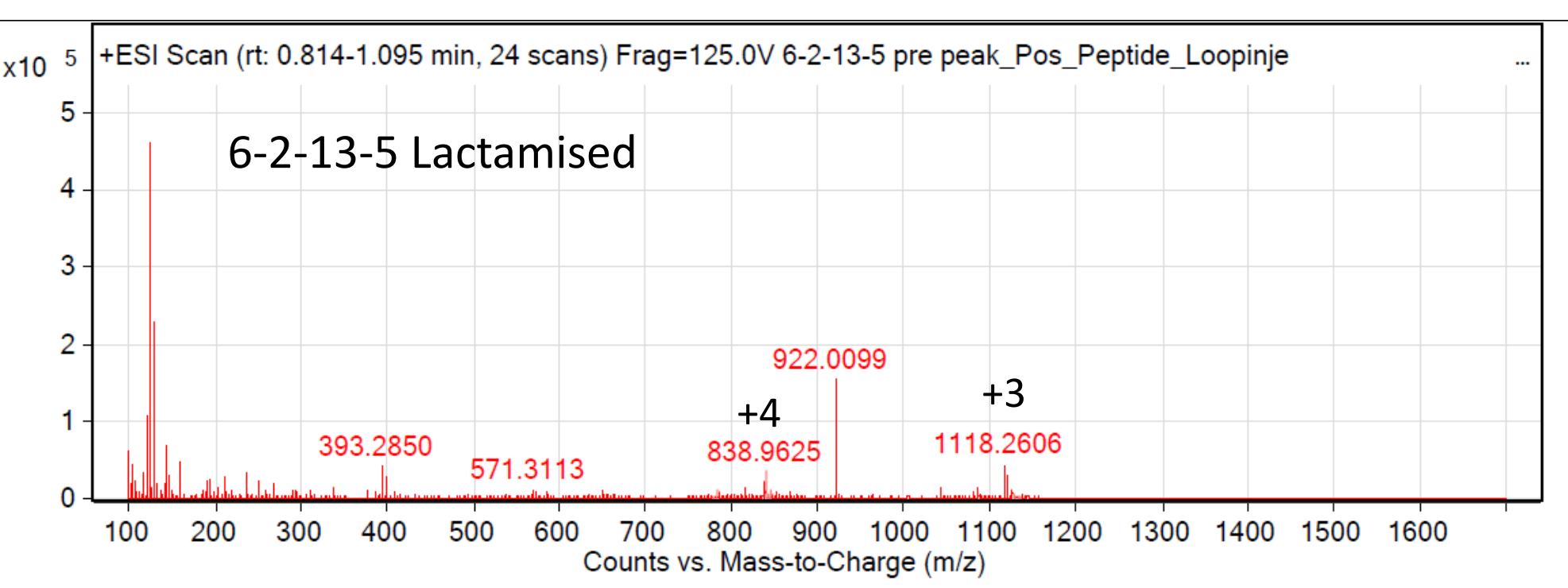

